Research Article

\title{
Effects of Reputation on Daily Deal Promotions: Evidence from Groupon
}

\author{
Junqiushi Ren \\ Research Institute of Economics and Management, Southwestern University of Finance and Economics, Chengdu 611130, China \\ Correspondence should be addressed to Junqiushi Ren; junqiushiren@yahoo.com
}

Received 1 September 2020; Revised 8 November 2020; Accepted 26 November 2020; Published 4 December 2020

Academic Editor: Erivelton Geraldo Nepomuceno

Copyright (c) 2020 Junqiushi Ren. This is an open access article distributed under the Creative Commons Attribution License, which permits unrestricted use, distribution, and reproduction in any medium, provided the original work is properly cited.

\begin{abstract}
Daily deals are nowadays very popular. As a new form of marketing, they allow local small businesses to sell vouchers at substantial price discounts for a very limited period of time. However, it is unclear whether and to what extent a seller's online reputation affects the outcomes of its daily deal promotions. This paper presents an analysis of 4060 daily deals scraped from Groupon. The empirical results suggest that (1) business reputation, measured by displayed average rating, is positively associated with the sales of vouchers; (2) business reputation has no significant relationship with voucher discount depth; (3) business reputation is positively associated with the increase of customer traffic following a daily deal promotion; and (4) ratings displayed on daily deal sites are more influential than ratings displayed on third-party review sites. These findings extend our understanding of daily deals and provide concrete guidance to merchants regarding how to attract more purchases and traffic through online deals as well as to platform owners by pointing out the value of reputation in moderating consumers' and merchants' behaviors.
\end{abstract}

\section{Introduction}

The daily deal model for e-commerce, which has exploded in popularity over the last few years, is a combination of retailing and marketing. Daily deals are online discount vouchers which are typically offered by local small businesses and advertised through deal sites. Common business categories include restaurants, beauty salons, movie theaters, and health workshops. Coupons are usually available for sale for 24 hours. Consumers may purchase these vouchers via computers or mobile apps and then normally have 120 to 360 days to redeem them at the businesses. After their deals are redeemed, consumers can return to deal sites to rate the businesses.

With the widespread use of computers and mobile apps, daily deal markets have been growing exponentially. According to IBISWorld (https://www.ibisworld.com/ united-states/market-research-reports/daily-deals-sitesindustry/, last accessed: February 28, 2020), the market size of daily deals in the US is anticipated to reach $\$ 6$ billion in 2019 , at an annualized growth rate of $12.5 \%$ from 2014 . As the top deal site, Groupon is reported to have 43.6 million unique active customers and over 1 million merchants by the fourth quarter of 2019 (https://www.statista.com/statistics/ 273245/cumulative-active-customers-of-groupon/, last accessed: February 28, 2020).

Daily deals can benefit merchants by bringing in a lot of customers who might otherwise be unaware of a business's existence. In fact, the deals are usually sold at substantial price discounts, at or above $45 \%$. With such deep discounts, most merchants may consider offering daily deals as a marketing activity rather than a direct means of generating revenue. Hence, the marketing effectiveness of a daily deal should be a key concern of the merchants.

It has been well noted that the effectiveness of daily deal promotions is determined by many factors, such as deal price, discount depth, and deal features including time constraint (examples include Dholakia [1], Coulter and Roggeveen [2], Zhang et al. [3], Eisenbeiss et al. [4]). The online reputation of the business, which is reflected by previous consumers' ratings and displayed prominently on a deal's webpage, should be an important factor as well.

This paper aims to examine whether and how business reputation influences the outcomes of daily deal promotions. 
For this purpose, a spider program is used to scrape daily deals from Groupon between January 1st and January 30th of 2018, which is then matched with a dataset obtained from Yelp. Several regressions are used to analyze the impacts of business reputation on different outcome variables. Specifically, the following hypotheses are formulated and tested:

$H 1$ : Online reputation is positively associated with the sales of daily deal vouchers.

H2: Online reputation is negatively associated with voucher discount depth.

H3: Online reputation is positively associated with the rise of customer traffic after daily deal promotions.

The rest of the paper is organized as follows: Section 2 reviews related literature. Section 3 briefly introduces the background knowledge of Groupon and Yelp. Section 4 outlines the data and the regression models. Section 5 describes the main results. Section 6 concludes the paper.

\section{Literature Review}

E-commerce, as many authors have pointed out (Kollock [5], Yamagishi and Matsuda [6], Resnick et al. [7], and Brown and Morgan [8], among others), is plagued by information asymmetries. Various reputational mechanisms have been introduced to remedy these problems, with review ratings being the most widely used tool. Consumers' reviews and ratings could provide information about the quality of the sellers as well as their products and services and hence could help potential consumers to update their beliefs and make purchase decisions.

However, while the role of consumer ratings in overcoming adverse selection problems is known (e.g., Hao et al. [9], Chen et al. [10], and Sahoo et al. [11]), the empirical validation of this claim generates mixed findings. While a considerable number of studies state that a higher average rating could increase product sales (Chevalier and Mayzlin [12], Chintagunta et al. [13], and Saeedi [14]), it has been admitted that the average rating may not necessarily influence consumers' purchasing behaviors due to at least two reasons. First, consumers may realize that online reviews could be biased and unreliable ( $\mathrm{Li}$ and Hitt [15] and Dellarocas [16]). Second, ratings could be helpless if they reveal a J-shaped distribution with mostly 5-star ratings, some 1-star ratings, and hardly any ratings in between ( $\mathrm{Hu}$ et al. [17]). It is thus not surprising that Liu [18] and Duan et al. [19] find that user reviews have little persuasive effect on consumer purchase decisions. Therefore, to date, whether a higher business reputation enhances product sales on e-commerce platforms is still an open empirical question.

Similarly, whether a higher business reputation could reduce discount rates in online transactions is an unaddressed question as well. While a few studies have pointed out the positive correlation between the final price of an item and the feedback that a seller has received (Melnik and Alm [20], Houser et al. [21], and Reiley et al. [22]), Yin [23] shows that the price and discount of an object are largely determined by the dispersion in the perceived value of the object instead of ratings and reviews.

In the context of daily deals, the empirical validation of whether business reputation could alleviate information asymmetries remains almost unexplored. Existing research on daily deals focuses on deal features such as time to expiration, coupon face value, previous buyer number, discount level, purchase limit, and product category (e.g., Dholakia [1], Coulter and Roggeveen [2], Zhang et al. [3], and Eisenbeiss et al. [4]). To the best of my knowledge, the only two works that tried to discuss online business reputation are $\mathrm{Li}$ [24] and $\mathrm{Li}$ [25]. While $\mathrm{Li}$ [24] confirms the impact of online ratings on social media endorsements, $\mathrm{Li}$ [25] suggests that businesses with a relatively low prior rating and a relatively small number of reviews may improve their online ratings by promoting on Groupon. This study differs from those two works by investigating the impacts of ratings from different aspects. Specifically, the author examines how ratings may affect voucher sales and discount rates, as well as customer flows, which are not explored in those two works. Besides, while Li [24] and Li [25] only used third-party ratings, the author includes both Groupon ratings and third-party ratings in this paper and attempt to compare the possibly different impacts of them.

In short, this study contributes to the literature by providing new empirical evidence regarding the role of reputation in e-commerce. As a relatively new form of e-commerce, daily deals are rarely discussed from the viewpoint of reputation and information asymmetries. This paper fills the gap. The findings provide useful insights to business managers regarding how to attract more purchases and traffic when offering deals and to platform owners by pointing out the value of reputation in moderating consumers' and merchants' behaviors.

\section{Background}

3.1. About Groupon. Groupon is the biggest daily deal website nowadays. Founded in 2008, Groupon provides deals covering a wide range from theater tickets and city passes to restaurant meals and Yoga classes. In this study, the author focuses on daily deals in the restaurant category, which is one of the most popular categories on Groupon.

Groupon provides a very good environment for researchers to study the effects of reputation on voucher sales and prices. From its webpages, the author can accurately collect the needed variables (e.g., voucher sales, average customer ratings, and discount depth), so that the effects could be quantified precisely. Figure 1 shows several screenshots of typical restaurant deals from Groupon. When consumers browse the webpages, they can easily see the characteristics of the deal, the restaurant name, face value of the voucher, discounted price, and the Groupon rating of the restaurant, which may potentially influence their decisions to buy the deal.

In addition, to identify the effect of displayed Groupon ratings, it is required that consumers be prevented from "interfering" in displayed ratings so that the possible reverse causality is avoided. Based on my inspection, the average 


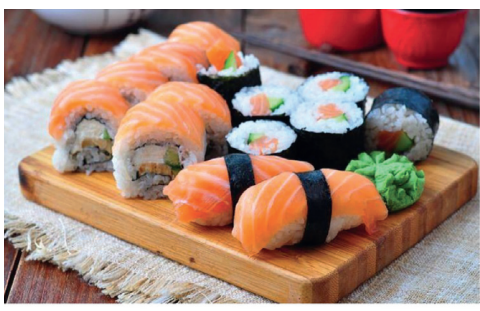

Hana Sushi, Chinese and Thai Restaurant \$\$. West Taylor Street, Chicago $4.1 \star \star \star \star \pi(147)$

$\$ 20$ Value

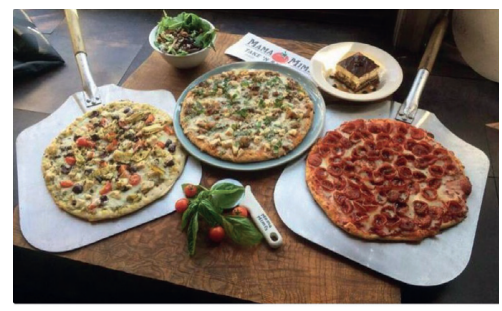

8 Mama Mimi's

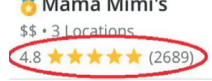
$\begin{array}{lr}\text { Two Large Menu Item Pizzas with Up to } & \$ 40.47 \$ 27.99 \\ \text { Four Toppings and Large Caesar or C... } & 30 \% \text { OFF }\end{array}$

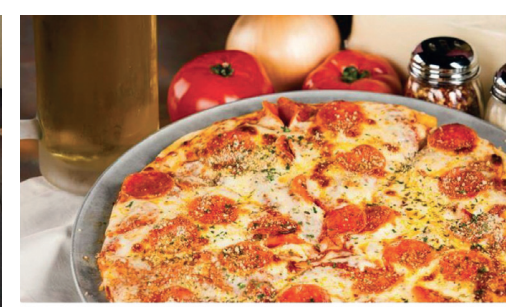

8 Red Brick Tap \& Grill

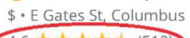

$\begin{array}{ll}\text { Visits for LUNCH- worth } \$ 10 \text { each } & \$ 30 \$ 15 \\ 50 \% \text { OFF }\end{array}$

FIGURE 1: Screenshots of typical restaurant deals from Groupon. Restaurants' Groupon ratings are often prominently displayed, which could potentially influence consumers to buy the deal.

ratings displayed on Groupon deal pages are mostly fixed during the deal promotion. Furthermore, since most restaurant deals are only sold for several days (typically three to four days) and the vouchers are often valid for redemption within a few months, consumers who buy vouchers are less likely to redeem them immediately and post review ratings online when the deal is still on sale. Therefore, displayed average ratings in this setting are largely predetermined and can be considered as exogenous.

3.2. About Yelp. Yelp is a third-party review platform which allows users to read and write reviews about local businesses. It is perhaps the most well-known and popular third-party site providing ratings and reviews about restaurants.

In general, Yelp ratings are not displayed on Groupon. However, when consumers find an interesting deal on Groupon, it is possible that they may further go to browse the corresponding restaurant on Yelp. Hence, the ratings on Yelp could also influence consumers' decisions to buy the deal. This study includes both Groupon ratings and Yelp ratings and makes a comparison between them.

Besides, as Yelp is very widely used, the number of reviews on Yelp may serve as a proxy of customer flows. By comparing the number of reviews posted before and after the date of the deal promotion, the author could approximately depict the changes in customer traffic caused by the deal. Similarly, the number of reviews on Yelp that mention the word "Groupon" may serve as a proxy of customer flows that are brought in by Groupon directly. Both proxies are used in this study in order to identify the changes in customer traffic.

\section{Method and Data}

4.1. Multivariate OLS Regressions. Multivariate OLS allows us to examine the effect of the variable of interest on a dependent variable while the effects of other variables are controlled for. In this study, multivariate OLS is the main method used to quantify the effects of business reputation.

The author the author drew twelve explanatory variables from existing studies (Duan [19], Dholakia [1], Coulter and Roggeveen [2], Zhang et al. [3], Eisenbeiss et al. [4], Li [24], and Cao et al. [26]). Each deal is characterized by its deal description, unit sales, actual (discounted) price, and ratings.

In particular, the key regression specification is given as

$$
\begin{aligned}
Y_{i j} & =\beta_{0}+\beta_{1} * \ln \text { Price }_{i j}+\beta_{2} * \ln \text { Discount }_{i j} \\
& +\beta_{3} * G_{-} \text {rating }_{i j}+\beta_{4} * Y_{-} \text {rating }_{i j}+\beta_{5} * \ln G_{-} \text {numreview }_{i j} \\
& +\beta_{6} * \ln Y \text { _numreview } \\
i j & +\beta_{7} * \text { Duration }_{i j}+\beta_{8} * \text { Soldout }_{i j} \\
& +\beta_{9} * \text { Time_to_redeem }_{i j}+\beta_{10} * \text { Weekday }_{i j} \\
& +\beta_{11} * \text { Multi_prom }_{i j}+\beta_{12} * \text { Designate }_{i j}+u_{i}+\varepsilon_{i j},
\end{aligned}
$$

for $i=1, \ldots, I$ cities and $j=1, \ldots, J_{i}$ daily deals in city $i$. The variables are explained in Table 1.

Since the main goal of this paper is to study the effects of reputation, $\beta_{3}$ and $\beta_{4}$ will be the key coefficients of interest which capture the relationship between reputation and outcome $Y$.

4.2. Data Collection. All data in this study are scraped from public sources. Specifically, data about deal description, unit sales, deal price, and Groupon ratings are extracted directly from Groupon website by using $R$.

The author samples 17 cities in the US, namely, Atlanta, Boston, Chicago, Dallas, Detroit, Houston, Las Vegas, Los Angeles, Miami, New Orleans, New York, Orlando, Philadelphia, San Diego, San Francisco, Seattle, and Washington DC. All restaurant deals in the sample cities between January 1st and January 30th of 2018 are collected. The author then drops the deal observations that have fewer than 10 reviews. This results in a cross-sectional dataset consisting of 4060 restaurant deals.

For each restaurant deal, the author manually checks if the restaurant has a profile on http://Yelp.com. For each restaurant with a Yelp profile, the author uses $R$ to extract its Yelp ratings and reviews, and then drop the restaurants with fewer than 10 reviews. Ultimately, the author assembles a subsample of 2212 deals which have both Yelp ratings and Groupon ratings. Table 2 reports the summary statistics of the key variables in my dataset. 
TABLe 1: Description of the model variables.

\begin{tabular}{|c|c|}
\hline Symbol & Description \\
\hline Y & Outcome variable, which is either ln (voucher sales) or a proxy of customer traffic brought in by the deal \\
\hline Price & Deal price \\
\hline Discount & Percentage price discount of the deal, calculated as $1-($ deal price/regular price) \\
\hline ting & Average consumer rating displayed on Groupon \\
\hline ting & Average consumer rating displayed on Yelp \\
\hline review & Number of reviews displayed on Groupon \\
\hline$Y_{-} \mathrm{n}$ & Number of reviews displayed on Yelp \\
\hline Duration & Promotion duration, \\
\hline out & e equal to 1 if the \\
\hline Time_to_redeem & Dummy variable equal to 1 if the voucher must be redeemed within 60 days after purchase, and 0 otherwise \\
\hline Weekday & Dummy variable equal to 1 if the deal promotion was on a weekday, and 0 otherwise \\
\hline Mul & variable equal to 1 if the restaurant conducts more than one deal prom \\
\hline Designate & Dummy variable equal to 1 if the deal is a designated meal, and 0 otherwise \\
\hline$u_{i}$ & City fixed effects \\
\hline$\varepsilon_{i j}$ & Normally distributed error term \\
\hline
\end{tabular}

TABLE 2: Summary statistics of key variables.

\begin{tabular}{|c|c|c|c|c|c|c|}
\hline & Mean & SD & Min & Max & Median & \# obs. \\
\hline \multicolumn{7}{|l|}{ Dependent variables: } \\
\hline Voucher sales & 856.40 & 1677.36 & 0 & 5300 & 610 & 4060 \\
\hline Proxy of customer traffic brought in by Groupon & 2.07 & 2.28 & 0 & 18 & 2 & 2212 \\
\hline \multicolumn{7}{|l|}{ Main explanatory variables: } \\
\hline Deal price $(\$)$ & 18.52 & 25.33 & 3 & 380 & 14 & 4060 \\
\hline Discount rate $(\%)$ & 50.97 & 9.21 & 15 & 83 & 45 & 4060 \\
\hline Avg. customer rating displayed on Groupon & 3.31 & 0.64 & 2.2 & 5 & 3.3 & 4060 \\
\hline Avg. customer rating displayed on Yelp & 3.53 & 0.56 & 1.5 & 5 & 3.5 & 2212 \\
\hline No. of reviews on Groupon & 21.24 & 43.17 & 10 & 2898 & 16 & 4060 \\
\hline No. of reviews on Yelp & 62.88 & 96.32 & 10 & 3065 & 33 & 2212 \\
\hline
\end{tabular}

\section{Results and Discussion}

5.1. Reputation and Voucher Sales. Table 3 presents the OLS estimates with ln (voucher sales) as the dependent variable. In Column (1), the author uses the full sample. In Column (2), the author uses the subsample which contains both Yelp ratings and Groupon ratings. In both columns, robust standard errors are used to alleviate heteroscedasticity. Besides, since error terms within a city may exhibit some degree of correlation, they are clustered for each city in order to account for possible within-city correlations.

According to the results, the significantly positive coefficients of displayed Groupon rating in both columns suggest that displayed Groupon ratings could affect voucher sales. Economically, Column (1) suggests that an extra onestar displayed Groupon rating increases voucher sales by $48.4 \%$, supporting $H 1$. When third-party ratings from Yelp are included, as presented in Column (2), an additional star of Groupon rating is still associated with a $42 \%$ increase in voucher sales, while an additional star of Yelp rating is associated with a $10.8 \%$ increase in voucher sales. The latter result indicates that Groupon ratings are much more influential than third-party ratings. This is not surprising, because Groupon ratings are prominently displayed on the deal page and every customer could see them easily, whereas third-party ratings are not displayed. In other words, ratings that are easy to see when consumers browse deals are more influential than ratings that are not easy to see.

It is worth commenting that the coefficient estimates of number of reviews in both columns are positive and significant, suggesting that restaurants with more reviews are likely to receive more voucher sales. This is consistent with prior research (e.g., Liu [18], Duan et al. [19], and Li [24]) which shows that the volume of reviews has a significant predictive power for product sales. Suppose that the volume of reviews is positively associated with previous buyer number; then, this result is also consistent with Coulter and Roggeveen [2] who reported that that previous buyer number could affect a consumer's decision to purchase.

The results also reveal that promotion duration has a significantly positive effect, indicating that when the deal is available for sale for more days, more coupons get sold. The dummies of designated meals turned out to be significantly negative, implying that consumers prefer freely chosen meals rather than designated meals. Moreover, the coefficient estimates of deal price are negative and estimates of discount rate are positive, which is consistent with law of demand and enhances our confidence about the credibility of the dataset.

One may doubt whether including both Groupon rating and Yelp rating in the same regression would cause multicollinearity. To test if this problem exists, the author further 
TABLE 3: Model results of reputation effect on voucher sales.

\begin{tabular}{|c|c|c|c|c|}
\hline \multirow{2}{*}{ Dependent variable: $\ln$ (voucher sales) } & \multicolumn{2}{|c|}{ (1) } & \multicolumn{2}{|c|}{$(2)$} \\
\hline & Coeff. & SE & Coeff. & SE \\
\hline $\ln ($ deal price) & $-1.131^{* * *}$ & 0.263 & $-1.301^{* * *}$ & 0.308 \\
\hline $\ln$ (discount rate) & $2.315^{* *}$ & 0.782 & $2.169^{* *}$ & 0.803 \\
\hline Avg. customer rating displayed on Groupon & $0.484^{* * *}$ & 0.131 & $0.420^{* *}$ & 0.159 \\
\hline Avg. customer rating displayed on Yelp & & & $0.108^{*}$ & 0.047 \\
\hline $\ln$ (no. of reviews on Groupon) & $0.573^{* * *}$ & 0.106 & $0.501^{* * *}$ & 0.130 \\
\hline $\ln ($ no. of reviews on Yelp) & & & $0.162^{*}$ & 0.083 \\
\hline Promotion duration & $0.161^{* * *}$ & 0.037 & $0.206^{* * *}$ & 0.044 \\
\hline Dummy of sold out & $0.102^{*}$ & 0.051 & 0.185 & 0.174 \\
\hline Dummy of redemption time & -0.042 & 0.047 & -0.037 & 0.040 \\
\hline Dummy of weekdays & -0.156 & 0.139 & -0.101 & 0.165 \\
\hline Dummy of multiple promotions & $-0.102^{*}$ & 0.056 & -0.065 & 0.053 \\
\hline Dummy of designated meals & $-0.066^{* * *}$ & 0.013 & $-0.074^{* * *}$ & 0.019 \\
\hline City fixed effects & Yes & & Yes & \\
\hline No. of observations & \multicolumn{2}{|c|}{4060} & \multicolumn{2}{|c|}{2212} \\
\hline White test $H_{0}$ : homoscedasticity & \multicolumn{2}{|c|}{$p$ value $=0.011$} & \multicolumn{2}{|c|}{$p$ value $=0.023$} \\
\hline$R^{2}$ & \multicolumn{2}{|c|}{0.311} & \multicolumn{2}{|c|}{0.335} \\
\hline
\end{tabular}

computes the correlation coefficient between the two variables (i.e., average consumer rating displayed on Groupon and Yelp) as well as the VIFs. The values are reported in Table 4. Based on the results, the correlation coefficient between the two variables is 0.451 , and the VIF for each variable is lower than 3.5 , which indicates some correlation, but not enough to be overly concerned about (Hair et al. [27] and Kennedy [28]). Hence, it should be safe to contain both ratings in the same model.

5.2. Reputation and Discount Rate. As Melnik and Alm [20] and Reiley et al. [22] noted, a seller's reputation may reduce information asymmetries and thereby correct the willingness of buyers to pay for a good, which may further influence the price, or say discount, in online transactions. To empirically validate this claim in the daily deals market, the author regresses ln (discount rate) on a set of predetermined explanatory variables, with cluster-robust standard errors being used to control for heteroscedasticity and within-city correlations. The results are presented in Table 5 .

In Column (1), the author uses the full sample. In Column (2), the author uses the subsample which contains both Yelp ratings and Groupon ratings. Empirically, the results show negative and significant correlations between deal discount rate and number of reviews, indicating that restaurants with more reviews (and more historical sales) are likely to offer smaller discounts. Deal discount rate is also correlated with deal features such as coupon face value and whether the coupon is a designated meal.

However, the coefficient estimates of displayed Groupon rating in both columns are negative but insignificant, indicating that the effect of displayed Groupon rating is minimal, rejecting $H 2$. Meanwhile, the coefficient estimate of displayed Yelp rating in Column (2) is also insignificant, suggesting that Yelp rating also has no effect on deal discount depth. This result is in contrast with Melnik and Alm
[20], Houser et al. [21], and Reiley et al. [22] who argued that the final price of an item (or discount depth) should be positively (or negatively) correlated with the rating that a seller has received.

5.3. Reputation and Customer Flows. As a marketing activity, whether a deal could effectively increase customer flows should be an important aspect to consider. Nonetheless, accurate data on customer flows is not available. Hence, the author uses an alternative approach to approximately capture the changes in customer flows. Specifically, the number of reviews on Yelp is used as a proxy of customer flows, and the number of reviews on Yelp which mention the word "Groupon" is used as a proxy of consumer traffic brought in by Groupon deals directly. By comparing the number of reviews posted before and after the date of the deal promotion, the author could approximately depict the changes in customer traffic caused by the deal.

Figure 2 portrays the trend of average review volume across all restaurants in the sample. According to the blue curve, average review volume fluctuates in a narrow range before Groupon deal. Once the deal is offered, the number of reviews significantly rises. This number remains at a relatively high level until the fourth month after the deal. Since then, the trend returns to the initial level and fluctuates slightly again. According to the orange curve, the number of reviews mentioning "Groupon" is close to zero before Groupon deal, clearly increases following the deal, and returns to initial level after four months. The patterns of these two curves are very similar, indicating that Groupon deal should be the main driver behind the changes. The fourmonth period is not surprising, since most Groupon deals must be redeemed within 60 to 120 days after purchase. Hence, this figure is consistent with our expectation and enhances our confidence in using number of reviews on 
TABLE 4: Test for multicollinearity.

\begin{tabular}{ll}
\hline Correlation between avg. consumer rating displayed on Groupon and avg. customer rating displayed on Yelp & $0.451^{* * *}$ \\
\hline VIF for avg. customer rating displayed on Groupon & 2.51 \\
VIF for avg. customer rating displayed on Yelp & 3.48 \\
Mean VIF & 2.08 \\
\hline
\end{tabular}

Note. ${ }^{*},{ }^{* *}$, and ${ }^{* * *}$, respectively, represent the significant level of $10 \%, 5 \%$, and $1 \%$. VIFs are calculated for the second model of Table 3 .

TABLE 5: Model results of reputation effect on voucher discount rate.

\begin{tabular}{|c|c|c|c|c|}
\hline \multirow{2}{*}{ Dependent variable: $\ln$ (discount rate) } & \multicolumn{2}{|c|}{ (1) } & \multicolumn{2}{|c|}{ (2) } \\
\hline & Coeff. & SE & Coeff. & SE \\
\hline $\ln$ (face value) & $0.103^{* *}$ & 0.036 & $0.010^{* *}$ & 0.035 \\
\hline Avg. customer rating displayed on Groupon & -0.185 & 0.148 & -0.206 & 0.162 \\
\hline Avg. customer rating displayed on Yelp & & & 0.103 & 0.355 \\
\hline $\ln$ (no. of reviews on Groupon) & $-0.065^{* *}$ & 0.025 & $-0.062^{* *}$ & 0.025 \\
\hline $\ln ($ no. of reviews on Yelp) & & & $-0.014^{*}$ & 0.008 \\
\hline Promotion duration & -0.049 & 0.049 & -0.078 & 0.068 \\
\hline Dummy of redemption time & 0.123 & 0.085 & 0.154 & 0.126 \\
\hline Dummy of weekdays & -0.052 & 0.133 & 0.032 & 0.193 \\
\hline Dummy of multiple promotions & -0.068 & 0.055 & -0.093 & 0.072 \\
\hline Dummy of designated meals & $0.027^{* *}$ & 0.012 & $0.024^{* *}$ & 0.011 \\
\hline City fixed effects & Yes & & Yes & \\
\hline No. of observations & \multicolumn{2}{|c|}{4060} & \multicolumn{2}{|c|}{2212} \\
\hline White test $H_{0}$ : homoscedasticity & \multicolumn{2}{|c|}{$p$ value $=0.056$} & \multicolumn{2}{|c|}{$p$ value $=0.062$} \\
\hline$R^{2}$ & \multicolumn{2}{|c|}{0.103} & \multicolumn{2}{|c|}{0.110} \\
\hline
\end{tabular}

Note. ${ }^{*},{ }^{* *}$, and ${ }^{* * *}$, respectively, represent the significant level of $10 \%, 5 \%$, and $1 \%$. Standard errors are heteroscedasticity-robust and are clustered by city.

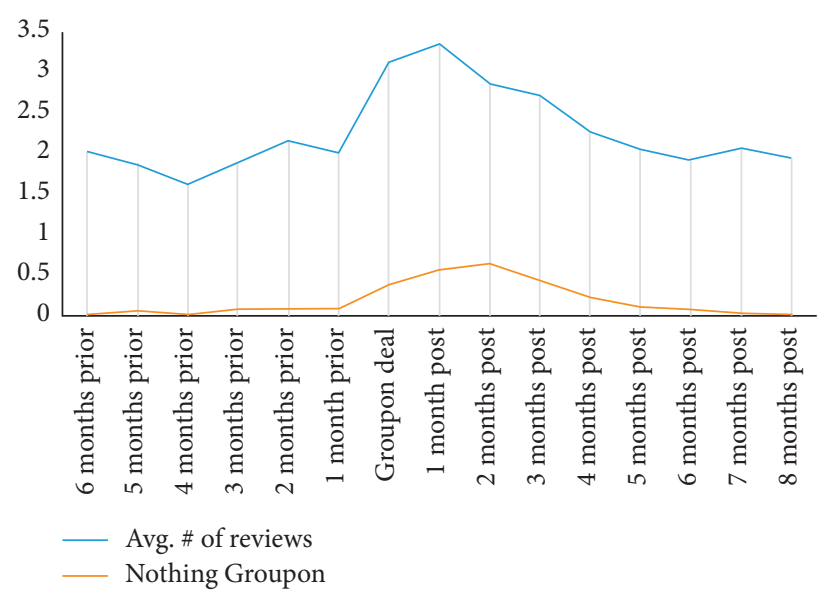

Figure 2: Monthly number of reviews posted on third-party website before and after Groupon deal. The horizontal axis represents the time before/after the Groupon deal. The blue curve illustrates the average monthly number of reviews on third-party website across all restaurants in the sample. The orange curve illustrates the average monthly number of reviews on third-party website which mention the word "Groupon" across all restaurants in the sample.

third-party website to approximately capture customer flows.

To investigate the relationship between reputation and customer flows brought in by the deal, the author then applies key regression (1), where the dependent variable is the number of reviews on Yelp which mention "Groupon" within four months after the deal. Standard errors are heteroscedasticity-robust and are clustered by city to account for possible within-city correlations of the residues. The estimation results are summarized in Table 6 .

In Column (1), the author uses OLS regression method. In Column (2), the author uses negative binomial regression method. In Column (3), the author uses zero-inflated negative binomial regression method in order to resolve the possible excess-zero problem (Hall [29] and Yau et al. [30]). (647 out of 2212 observations (pct. $=29.2 \%$ ) have the 
TABLE 6: Model results of reputation effect on customer traffic rises.

\begin{tabular}{|c|c|c|c|c|c|c|}
\hline \multirow{2}{*}{ Dependent variable: proxy of customer traffic rises } & \multicolumn{2}{|c|}{ (1) } & \multicolumn{2}{|c|}{$(2)$} & \multicolumn{2}{|c|}{ (3) } \\
\hline & Coeff. & SE & Coeff. & SE & Coeff. & SE \\
\hline $\ln ($ deal price $)$ & $-0.109^{*}$ & 0.052 & $-0.115^{*}$ & 0.069 & -0.060 & 0.051 \\
\hline $\ln ($ discount rate) & 0.009 & 0.033 & 0.010 & 0.045 & 0.066 & 0.073 \\
\hline Avg. customer rating displayed on Groupon & $0.242^{*}$ & 0.131 & $0.205^{*}$ & 0.121 & $0.305^{*}$ & 0.170 \\
\hline Avg. customer rating displayed on Yelp & 0.102 & 0.119 & 0.147 & 0.130 & 0.183 & 0.125 \\
\hline $\ln ($ no. of reviews on Groupon) & $0.111^{*}$ & 0.059 & $0.072^{*}$ & 0.037 & $0.190^{* *}$ & 0.074 \\
\hline $\ln ($ no. of reviews on Yelp) & 0.024 & 0.020 & $0.025^{*}$ & 0.013 & 0.078 & 0.107 \\
\hline Promotion duration & $0.218^{* *}$ & 0.080 & $0.226^{* *}$ & 0.079 & $0.285^{*}$ & 0.155 \\
\hline Dummy of sold out & -0.055 & 0.341 & -0.046 & 0.325 & 0.029 & 0.282 \\
\hline Dummy of redemption time & 0.063 & 0.604 & 0.101 & 0.555 & 0.139 & 0.140 \\
\hline Dummy of weekdays & -0.118 & 0.090 & -0.139 & 0.103 & 0.205 & 0.230 \\
\hline Dummy of multiple promotions & 0.013 & 0.140 & 0.017 & 0.112 & 0.153 & 0.412 \\
\hline Dummy of designated meals & -0.200 & 0.180 & -0.208 & 0.184 & -0.089 & 0.130 \\
\hline City fixed effects & Yes & & Yes & & Yes & \\
\hline No. of observations & \multicolumn{2}{|c|}{2212} & \multicolumn{2}{|c|}{2212} & \multicolumn{2}{|c|}{2212} \\
\hline White test $H_{0}$ : homoscedasticity & \multicolumn{2}{|c|}{$p$ value $=0.047$} & & & \multirow{2}{*}{\multicolumn{2}{|c|}{0.105}} \\
\hline$R^{2} /$ Pseudo $R^{2}$ & & & \multicolumn{2}{|c|}{0.124} & & \\
\hline
\end{tabular}

dependent variable equal to zero.) In all columns, the coefficient estimates of the number of reviews are positive, which is in line with the findings in Section 5.1. The estimates of promotion duration are positive, indicating that when the deal is exposed for more days, more customers get attracted. What is more, the coefficient estimates of displayed Groupon rating are positive and significant in all columns, which suggests that reputation has a positive impact on the rises of customer flows, supporting $H 3$. Once again, the estimates of displayed Groupon rating are obviously greater than those of Yelp ratings, implying that ratings from deal sites are more effective in terms of stimulating consumer traffic than ratings from third-party review sites.

\section{Conclusions and Discussion}

This article studies whether and how a seller's online reputation affects the outcomes of its daily deal promotions. Based on data scraped from the biggest daily deal website, Groupon, and the most popular third-party review website, Yelp, the author obtains a few important findings. First, online reputation is positively associated with the sales of vouchers. Second, online reputation has no significant relationship with voucher discount depth. Third, online reputation is positively associated with the increase of customer traffic following the deal. Last but not least, ratings from deal sites are more influential than ratings from thirdparty review sites.

This paper offers three important contributions. First, to date, whether a higher business reputation enhances product sales and whether it depresses discount rates on e-commerce platforms are two controversial questions. This study provides new empirical evidence to these questions and contributes to the literature. Second, as a relatively new industry, daily deals are rarely discussed from the viewpoint of reputation and information asymmetries. This paper fills the gap. Third, the findings provide useful insights to merchants about how to attract more purchases and traffic through online deals and to platform owners by pointing out the value of reputation in moderating consumers' and merchants' behaviors.

To enable readers to interpret the results accurately, it is necessary to recognize the limitations of this study. Due to limitations of the data, the measurement of customer traffic may not be accurate. Future research may need to investigate this question using other data, such as restaurant revenue data, when available. Future research may also try to use panel data instead of cross-sectional data to redo the process presented here, so that the unobserved time-invariant heterogeneity can be controlled as Duan et al. [19] suggest.

\section{Data Availability}

The data used to support the findings of this study are available from the author upon request.

\section{Conflicts of Interest}

The author declares no conflicts of interest.

\section{Acknowledgments}

The author would like to appreciate Professor Maryam Saeedi from Carnegie Mellon University for her valuable comments and assistance. 


\section{References}

[1] U. M. Dholakia, "What makes Groupon promotions profitable for businesses?," 2011, https://ssrn.com/ abstract $=1790414$.

[2] K. S. Coulter and A. Roggeveen, "Deal or no deal?" Journal of Research in Interactive Marketing, vol. 6, no. 2, pp. 78-95, 2012.

[3] Z. Zhang, Z. Zhang, F. Wang, R. Law, and D. Li, "Factors influencing the effectiveness of online group buying in the restaurant industry," International Journal of Hospitality Management, vol. 35, pp. 237-245, 2013.

[4] M. Eisenbeiss, R. Wilken, B. Skiera, and M. Cornelissen, "What makes deal-of-the-day promotions really effective? the interplay of discount and time constraint with product type," International Journal of Research in Marketing, vol. 32, no. 4, pp. 387-397, 2015.

[5] P. Kollock, "The production of trust in online markets," Advances in Group Processes, vol. 16, no. 1, pp. 99-123, 1999.

[6] T. Yamagishi and M. Matsuda, "Improving the lemons market with a reputation system: an experimental study of internet auctioning," Technical Report, University of Hokkaido, Sapporo, Japan, 2002.

[7] P. Resnick, R. Zeckhauser, J. Swanson, and K. Lockwood, "The value of reputation on eBay: a controlled experiment," Experimental Economics, vol. 9, no. 2, pp. 79-101, 2006.

[8] J. Brown and J. Morgan, "Reputation in online auctions: the market for trust," California Management Review, vol. 49, no. 1, pp. 61-81, 2006.

[9] L. Hao, X. Li, Y. Tan, and J. Xu, "The economic value of ratings in app market," 2011, https://ssrn.com/abstract=1892584.

[10] Y. Chen, S. Fay, and Q. Wang, "The role of marketing in social media: how online consumer reviews evolve," Journal of Interactive Marketing, vol. 25, no. 2, pp. 85-94, 2011.

[11] N. Sahoo, C. Dellarocas, and S. Srinivasan, "The impact of online product reviews on product returns," Information Systems Research, vol. 29, no. 3, pp. 723-738, 2018.

[12] J. A. Chevalier and D. Mayzlin, "The effect of word of mouth on sales: online book reviews," Journal of Marketing Research, vol. 43, no. 3, pp. 345-354, 2006.

[13] P. K. Chintagunta, S. Gopinath, and S. Venkataraman, "The effects of online user reviews on movie box office performance: accounting for sequential rollout and aggregation across local markets," Marketing Science, vol. 29, no. 5, pp. 944-957, 2010.

[14] M. Saeedi, "Reputation and adverse selection: theory and evidence from eBay," The RAND Journal of Economics, vol. 50, no. 4, pp. 822-853, 2019.

[15] X. Li and L. M. Hitt, "Self-selection and information role of online product reviews," Information Systems Research, vol. 19, no. 4, pp. 456-474, 2008.

[16] C. Dellarocas, "Strategic manipulation of internet opinion forums: implications for consumers and firms," Management Science, vol. 52, no. 10, pp. 1577-1593, 2006.

[17] N. Hu, J. Zhang, and P. A. Pavlou, "Overcoming the J-shaped distribution of product reviews," Communications of the ACM, vol. 52, no. 10, pp. 144-147, 2009.

[18] Y. Liu, "Word of mouth for movies: its dynamics and impact on box office revenue," Journal of Marketing, vol. 70, no. 3, pp. 74-89, 2006.

[19] W. Duan, B. Gu, and A. B. Whinston, "Do online reviews matter?-an empirical investigation of panel data," Decision Support Systems, vol. 45, no. 4, pp. 1007-1016, 2008.
[20] M. I. Melnik and J. Alm, "Does a seller's ecommerce reputation matter? evidence from eBay auctions," The Journal of Industrial Economics, vol. 50, no. 3, pp. 337-349, 2002.

[21] D. Houser and J. Wooders, "Reputation in auctions: theory, and evidence from eBay," Journal of Economics, vol. 15, no. 2, pp. 353-369, 2006.

[22] D. Reiley, D. Bryan, N. Prasad, and D. Reeves, "Pennies from eBay: the determinants of price in online auctions," The Journal of Industrial Economics, vol. 55, no. 2, pp. 223-233, 2007.

[23] P. L. Yin, "Information dispersion and auction prices," Stanford Institute for Economic Policy Research, Stanford, CA, USA, Working Paper, 2006.

[24] X. Li, "Impact of average rating on social media endorsement: the moderating role of rating dispersion and discount threshold," Information Systems Research, vol. 29, no. 3, pp. 739-754, 2018.

[25] X. Li, "Could deal promotion improve merchants' online reputations? the moderating role of prior reviews," Journal of Management Information Systems, vol. 33, no. 1, pp. 171-201, 2016.

[26] Z. Cao, K. L. Hui, and H. Xu, "When discounts hurt sales: the case of daily-deal markets," Information Systems Research, vol. 29, no. 3, pp. 567-591, 2018.

[27] J. F. Hair, R. E. Anderson, B. J. Babin, and W. C. Black, Multivariate Data Analysis, Pearson, Upper Saddle River, NJ, USA, 7th edition, 2010.

[28] P. Kennedy, A Guide to Econometrics, The MIT Press, Cambridge, MA, USA, 3rd edition, 1992.

[29] D. B. Hall, "Zero-inflated Poisson and binomial regression with random effects: a case study," Biometrics, vol. 56, no. 4, pp. 1030-1039, 2000.

[30] K. K. Yau, K. Wang, and A. H. Lee, "Zero-inflated negative binomial mixed regression modeling of over-dispersed count data with extra zeros," Biometrical Journal: Journal of Mathematical Methods in Biosciences, vol. 45, no. 4, pp. 437-452, 2003. 